\title{
Öz-yeterlilik ve İç Denetim Odağının Yenilikçi İş Davranışına Etkisi: Konaklama İşletmelerine Yönelik Bir Araştırma
}

\section{Esra TÖRE ${ }^{1}$}

Öz

Yeniliğe ve yenilikçi iş davranışı sergileyen çalışanlara olan ihtiyaç gün geçtikçe artmaktadır. Yenilikçi iş davranışı, herhangi bir organizasyon düzeyinde, yararlı bir yeniliğin geliştirilmesi, tanıtılması ve uygulanması yönündeki tüm bireysel faaliyetleri içerir. Bu çalışma, öz-yeterlilik ve iç denetim odağının, yenilikçi iş davranışı üzerindeki etkisinin incelemesi amacı ile yapılmışıtı. Çalışma nicel araştırma yöntemlerinden ilişkisel tarama modeline dayalı olarak tasarlanmıştır. Antalya'da bulunan 5 yıldızlı konaklama işletmelerinde çalışan 82.533 kişi çalışma evrenini oluşturmaktadır. Örneklemin belirlenmesinde kota örnekleme yöntemi kullanılmıştır. 439 anket değerlendirmeye alınmış, uygulama sırasında anket formu katılımcılara yüz yüze ulaştırılmışıı. Verilerin toplanmasında Kişisel Bilgi Formu, Yenilikçi İş Davranışı Ölçeği, Genel Öz-yeterlilik Ölçeği ve Denetim Odağı Ölçeği kullanılmıştır. Yanıtlar hazır istatistik paket programı tarafindan analiz edilmiştir. Araştırma hipotezini doğrulama için çoklu doğrusal regresyon analizi yapılmıştır. Araştırma sorularını yanıtlamada, katılımcıların demografik ve işe ilişkin özelliklerine göre ayrı ayrı gruplarda bağlantısız örneklemler için t testi ve ANOVA testi uygulanmıştır. Araştırma bulguları katılımcılara ilişkin demografik bulgular, faktör analizi bulguları ve hipotezlerin testine ilişkin bulgular olarak üç başlıkta sunulmuştur. Araştırma sonucunda öz-yeterliliğin ve iç denetim odağının yenilikçi iş davranışını anlamlı ve olumlu etkilediği bulunmuştur. Bulgular tartışılmış, araştırmacılara ve sektöre ilişkin önerilerde bulunulmuştur.

Anabtar Kelimeler: Yenilikçi İş Davranışı, Öz-Yeterlilik, İç Denetim Odağı, Turizm

\section{The Effect of Self-Efficacy and Internal Locus of Control on Innovative Work Behavior:} A Research on Hospitality Industry

\section{Abstract}

The need for employees who exhibit innovation and innovative business behavior is increasing day by day. Innovative work behavior involves any individual activity at the level of any organization, including the development, promotion and implementation of a useful innovation. This study was conducted to investigate the effect of selfefficacy and internal locus of control on innovative work behavior. The study was designed based on the relational screening model of quantitative research methods. 82.533 people working in 5 star accommodation establishments in Antalya constitute the target population of the study. Quota sampling method was used to determine the sample. 439 questionnaires were taken into consideration and the questionnaire was delivered face to face during the application. Personal Information Form, Innovative Work Behavior Scale, General Self-Efficacy Scale and Locus of Control Scale were used for data collection. Responses were analyzed by a ready-to-use statistical package program. Multiple linear regression analysis was performed to confirm the research hypothesis. In order to answer the research questions, t-test and ANOVA test were used for unrelated samples according to the demographic and work-related characteristics of the participants. The findings of the study are presented in three headings as demographic findings, factor analysis findings and findings related to the test of hypotheses. As a result of the research, it has been found that self-efficacy and internal control focus affect the innovative work behavior significantly and positively. The findings were discussed and recommendations were made to the researchers and the sector.

Key Words: Innovative Work Behavior, Self-Efficacy, Internal Locus of Control, Tourism

\section{Atıf İçin / Please Cite As:}

Töre, E. (2020). Öz-yeterlilik ve iç denetim odağının yenilikçi iş davranışına etkisi: Konaklama işletmelerine yönelik bir araştırma. Manas Sosyal Araştırmalar Dergisi, 9(1), 155-167. 


\section{Giriş}

Küreselleşmenin de etkisi ile değişime olan ihtiyaç gün geçtikçe artmakta, işletmeler arası rekabet yoğunlaşmaktadır. Yoğun rekabet ortamında işletmelerin temel hedefi, ayakta kalmak ve sürdürülebilir büyüme gerçekleştirmektir. Bu hedef yeniliğe ve yenilikçi iş davranışı sergileyen çalışanlara olan ihtiyacın artmasina neden olmaktadir.

Schumpeter (1934) ekonomik gelişmeyi, Drucker (1998, s. 150) ise uzun vadeli firma performansını yenilik ile ilişkilendirir. Değiş̧en çevre koşullarına uyum, verimlilik ve esneklik gibi konulara önemli katkı sağlayan yenilik, küresel rekabet ortamında uzun vadede örgütsel başarıyı arttıran bir unsurdur. Günümüzde işletmeler, çalışanın yenilikçi iş davranışının süreç geliştirme ya da ürün farklılaştırma yolları ile düşük maliyet ile sonuçlandığını kabul etmektedirler (Schimansky, 2014, s. 1). Bu durum yenilikçi çalışanın varlığını zorunlu hale getirmektedir. Bu çalışma kapsamında öz-yeterlilik ve iç denetim odağının yenilikçi iş davranışı üzerindeki etkisi incelenecektir.

Yenilikçi iş davranışı, herhangi bir organizasyon düzeyinde, yararlı bir yeniliğin geliştirilmesi, tanıtılması ve uygulanması yönündeki tüm bireysel faaliyetlerdir (West ve Farr, 1989, s. 17). Yeni teknolojileri gözlemleyen, yeni stratejileri kullanarak hedeflere ulaşmaya çalışan, yeni iş metotlarını uygulayan, yeni fikirlerin uygulanması için kaynak yaratan ve bu fikirleri destekleyen davranışlar, yenilikçi iş davranışına örnektir (Kheng vd., 2013, s. 93). Yeniliğin yalnızca bir fikir değil, aynı zamanda uygulama olması (Eveleens, 2010, s. 2), bu uygulamayı gerçekleştirecek çalışanların önemini ön plana çıkarmaktadır.

Scott ve Bruce (1994, s. 582) yenilikçi iş davranışını problemlerin tanımlanması, fikir ve çözümlerin üretilmesi, fikirleri destekleyecek alt yapıların oluşturulması ve fikirlerin uygulanmasını kapsayan çok aşamalı bir süreç olarak tanımlar. Yenilikçi iş davranışı, bir iş rolü, grup veya örgüt içinde fayda sağlamak için bilinçli olarak yeni fikirlerin yaratılması, tanıtımı ve uygulanmasıdır. Yenilikçi iş davranışı sürecinde fırsatlar keşfedilir, fikir üretilir, savunulur ve uygulanır (Çapraz vd., 2014, s. 51-53.) Yenilikçi iş davranış1 bir başka deyişle, yeni teknoloji ve tekniklerin geliştirilmesi, amaçlarnn gerçekleştirilmesi yönünde yeni yolların/yöntemlerin önerilmesi, çalışma alanında iş usullerine ilişkin yeni yöntemlerin denenmesi, çalışma rutinlerinin değiştirilmesi, yeni fikirlerin geliştirilmesi ve yeni yöntemlerin uygulanmasını içermektedir (Sönmez, 2011, s.5).

Yenilikçi iş davranışı, yaratıcillğın ötesinde uyarlama, üretim, yeni olanın uygulanması ve kullanışlı fikirleri içerir (Hasiao vd., 2011, s. 233). Beklenen sonuçlara yönelik uygulamalı öğeleri kapsar (Jong, 2007, s. 20). Yenilikçi iş davranışı sergileyen çalışan, bilinçli olarak ürün, prosedür ve süreçlere ait yeni fikirleri benimser (Çalışkan, 2013, s. 95); bu fikirleri kendi işine, bölümüne veya işletmenin tamamına uygular. Araştırmacılar yenilikçi iş davranışını etkileyen faktörleri, bireysel faktörler, işin özellikleri ve çevreye ilişkin faktörler ile örgütsel faktörler olmak üzere 3 temel kategoride değerlendirmektedirler (De Jong, 2007, s. 30; Sönmez, 2011, s. 66). Çapraz ve arkadaşları (2014, s. 51) yaptıkları araştırmada, yenilikçi iş davranışının oluşumunda çalışanların bireysel özelliklerinin, örgütsel özelliklerin önüne geçtiğini belirtmişlerdir. Çalışanın içsel ilgisi, yenilikçilikten çıkan performans çıktıları, yenilikçilikten beklediği olumlu imaj, fikir üretmesi ve farkındalık, çalışanları yenilikçi davranmaya yönlendirmektedir.

Bandura’nın (1997, s. 158) Sosyal Öğrenme Kuramı’nda ön plana çıkan öz-yeterlilik, bireyin kendisine verilen işi organize edebilme ve başarabilme yeteneği ile ilgili yargılarıdır. "Bireylerin olası durumlar ile başa çıkabilmek için gerekli olan eylemleri ne kadar iyi yapabildiklerine dair yargıları", onların öz-yeterlilik algisını tanımlar (Parlar, 2009, s. 12; Pekmezci, 2010, s. 23). Birey bir sonuca ulaşabileceğine inanırsa, daha aktif davranmakta ve yaşamının kontrolünü elinde tutabilmektedir.

Öz-yeterlilik, kişinin belli bir konuda yetenekli olması değil; o konuda kendi kaynaklarına güvenmesi anlamına gelir (Yıldırım ve İlhan, 2010, s. 2). Bir durumla baş etmede yeterli becerileri olan, ancak özyeterliliği düşük olan kişi, söz konusu becerilerini harekete geçiremeyecektir. Öz-yeterliliği yüksek olan insanlar, kendi yaşamlarını etkileyecek olaylar üzerinde etkili olduklarına inanırlar. Engel çıkması durumunda hayal kırıklığı ile baş edebilir, yüksek bağllı1k ve performans gösterebilirler. Amaçlarına meydan okurcasına hedeflerine güdülenirler. Başarısızlık olması durumunda, kendilerini hemen toparlar, hatayı yetersiz çabaya, eksik bilgiye ve becerilere yorarlar (Bandura, 1994, s. 158; Hasiao vd., 2011, s. 233 Parlar, 2009, s. 13).

Bandura'ya (1994, s. 159) göre öz-yeterlilik inancının yaşamda önemi büyüktür. Bireylerin öz-yeterlilik inançları, kişinin olumlu ya da olumsuz düşünmesini, yaşamda nasıl amaçlar belirleyeceğini, nasıl bir yaşam biçimi olacağını, zorluklar karşısında ne derece çaba harcayacağını, çabalarının ürününün nasıl olacağını 
etkiler (Bozkurt, 2013, s. 33). Bandura, öz-yeterlilik inancının oluşumunda geçmiş performansın, psikolojik durumun, deneyimlerin ve sözel ikna yeteneğinin etkili olduğunu belirtir (Potosky ve Ramakrishna, 2002, s.280).

Öz-yeterlilik, ustalık tecrübesi, temsili deneyim, sözel ikna, fiziksel ve duygusal durum olmak üzere 4 farklı şekilde oluşabilir (Bandura, 1994, s. 160; Parlar 2009, s. 15-18). Ustalık tecrübesi, geçmişte önemli başarılar edinmiş kişilerin önlerine bir engel çıktı̆ında 1srarcı olarak çabalamaya devam edebilmesidir. Temsili deneyim, kişilerin bir işi kendileri deneyimlememelerine rağmen, çevredeki deneyimleyen kişiler ile kendilerini kıyaslayarak, neler yapabilecekleri ile ilgili fikir sahibi olmalarıdır. Sözel ikna, sahip olunan becerilere yönelik, kişinin çevresinden aldığı olumlu geri bildirimleri içerir. Son olarak fiziksel ve duygusal durum ise; kişilerin bir işi yaparken deneyimledikleri fizyolojik ve duygusal reaksiyonları ifade eder. Fiziksel durumun iyileşmesi, olumlu duygulanımın artması öz-yeterliliğe katkı sağlar.

Öz-yeterlilik inancı, bireylerin istekliliğini, hedeflere ulaşma çabasını, güdülenme düzeylerini, zorlukla karşılaştıklarında vazgeçmemelerini, analitik düşünce becerilerini, başarı ve başarısızlı̆̆ değerlendirme biçimlerini, stres ve depresyona yatkınlık derecelerini belirlemede etkilidir (Onan, 2011, s. 15). Özyeterliliğe sahip insanlar daha zengin bilişsel kaynaklara ve esnek stratejilere sahiptirler, farklı alanlara ilgi duyarlar, firsatlara odaklanarak, geleceğe yönelik bakış açısı geliştirirler. Zorlu işleri seçer, iyimser ve kötümser senaryolar kurarlar. Başladıkları işleri sürdürme eğilimindedirler (Parlar, 2009, s. 18; Pekmezci, 2010, s. 24). Tüm bu özelliklerin yenilikçi bireyin özellikleri ile örtüştüğü görülmektedir.

Jong (2014, s. 28), yenilikçi iş davranışı sürecinin son aşaması olan uygulamayı, gereksinimlerin fikirden gerçekliğe transfer edilmesi olarak tanımlar. Yenilikçi iş davranışı, yeni ürünlerin ve iş süreçlerinin geliştirilmesi, değiştirilmesi, test edilmesini içerir. Bu uygulamalar için inisiyatif kullanan, sabırlı, engelleri aşabilen, süreci kendiliğinden başlatan, iş tanımında olmayan işleri de yapan çalışanlara ihtiyaç vardır. Özyeterliliği olan çalsşanlar, uygulama aşamasında daha başarılı olacaklardır. Çünkü öz-yeterlilik mevcut durumda yapılan değişimlerin başarıya ulaşacağına dair inancı destekler.

Hasio ve arkadaşları (2011, s. 235) öğretmenler üzerinde yaptıkları çalışmalarında, öz-yeterliliği yüksek çalışanların, diğer çalışanlara göre daha fazla fikir ürettiğini, yenilikçi fikirleri desteklediğini ve uyguladığını bulmuşlardır. Basım ve arkadaşları (2008, s. 121), kamu çalşsanları üzerinde yaptıkları araştırmada, özyeterlilik algısı ile yenilikçi iş davranışı arasında olumlu bir ilişki bulmuşlardır. Çalışan öz-yeterliliği yenilikçi iş davranışını pozitif ve anlamlı etkilemekte iken; yüksek düzeydeki öz-yeterlilik yüksek düzeyde yenilikçi iş davranışını ortaya çıkarmaktadır (Momeni vd., 2014, s. 29; Hsu vd., 2011, s. 627).

Denetim odağı kavramı, Rotter'ın sosyal öğrenme kuramının yapıtaşını oluşturmaktadır. Rotter (1966) denetim odağını, kişinin yaşamsal eylemlerinin kendi tarafından ya da diğerleri/diğer çevresel unsurlar tarafindan kontrol edildiğine dair inancı olarak tanımlar. Kişilerin kendi yaşamlarını denetleyebilme güçleri bakımından birbirlerinden farklı olduğunu gözlemleyen Rotter, kişilikle ilgili geliştirmiş olduğu bu boyutun bir ucuna "iç denetim odağı", diğer ucuna ise "dış denetim odağı" adını vermiştir (Çakır, 2009, s. 95, Erbin-Roesemann ve Simms, 1997, s. 185).

İç denetim odağı, bireylerin karşılaştı̆̆ı olayları, kendi davranışlarına bağlı olarak algıllaması ve sonuçlarının kendi elinde olduğuna inanma eğilimidir. İç denetim odağına sahip kişiler, kendi sorumluluklarının farkındadırlar, eylemlerinin olumlu ya da olumsuz sonuçlarını üstlenirler. Dış denetim odağı ise, bireyin karşılaştı̆̆ı olayların sonuçlarını kendi davranışlarıyla değil, kendi dışındaki güçlerin (kader, şans, otorite vb) etkisi ile meydana geldiğine inanmasıdır (Çakır, 2009, s. 96-97, Oliver vd, 2006, s. 835-836). Dış denetim odağına sahip bireyler, başarısızlıklarında dış çevre koşullarının, kendileri dışındaki faktörlerin etkili olduğunu düşünürler.

Araştırmalar (Canbay, 2007, s. 62, Aktaş, 2008, s. 4; Ertürk, 2012, s. 29), iç denetimlilerin daha aktif, daha girişimci ve mücadeleci, yüksek derecede olumlu benlik kavramına sahip, daha uyumlu, duygusal yönden daha sağlıklı ve dengeli olduklarını ortaya koymaktadır. İç denetimliler, çevresel uyaran ve ipuçlarını daha kolay algılayıp değerlendirebilmektedirler. Dış denetimliler ise düşük beklenti düzeyine sahip, kendilerini kabul düzeyleri düşük, daha kaygıll, pasif ve kuşkucudurlar.

İç denetim odağına sahip bireyler, dış denetim odaklı bireylerle kıyaslandığında; iç denetim odaklıların kendilerine bakış açılarının daha olumlu olduğu, yaratıcı oldukları, kendi yeteneklerine daha fazla güvendikleri, başarıya daha fazla değer verdikleri, işlerini daha fazla sevdikleri, bir konu hakkında karar vermeden önce uzun süre düşündükleri ve akademik açıdan daha başarılı oldukları tespit edilmiştir 
(Dönmez, 1986, s. 259). İçten denetimliler, öğrenmeye açık, meraklı, araştıran ve bilgi işleme sürecinde etkili bireylerdir (Sürgen, 2014, s. 32).

İç denetim odağına sahip bireyler, iş ortamını kontrol edebileceklerine inanırlar, yapılan işlerle ilgili kendilerini güçlendirilmiş hissederler. Dış denetim odağına sahip bireyler ise iş ortamının dış güçler tarafından kontrol edildiğini, kendilerinin etkisinin olmadığını düşünürler (Wnag vd, 2013, s. 1429).

Denetim odağ1, birçok kişilik özelliğiyle oldukça sağlam ilişkiler göstermektedir. İç denetim odağ1 inancının, daha iyi bir duygusal uyumla, bir başka deyişle psikolojik sorunların azlı̆̆yla, öznel iyilik hali ve stresle daha iyi başa çıkabilmeyle ilişkili olduğu pek çok araştırmacı tarafindan bildirilmiştir. Dış denetim odağı ise normal ötesi inanışlara sahip olma ile ilişkili bulunmaktadır (Dağ, 2002, s. 78).

Luthans (1998, s. 183), denetim odağı kavramı ile çalışan davranışlarının açıklanabileceğini belirtir. Çalışan denetimi içten algılıyorsa, kendi sonuçlarını yeteneği, becerisi veya çabalarıyla etkileyebileceğini düşünür. Dıştan algiliyor ise, sonuçlarının kendi kontrolünün ötesinde olduğunu düşünür. Girişimci nitelikleri ile öne çıkan iç denetim odaklılar, katılımcı yönetim stilini daha doyurucu bulurlar. Rutin, beceri geliştirmeyi gerektirmeyen işlerde çalsşmak yerine; yaratıcllı ve yenilikçilik içeren işlerde çalışmak isterler (Çakır, 2009, s. 99-100). Yeni firsatlar arayan ve yenilikçi tutumlar gösteren girişimcilerin, kendi yaşamlarındaki olayları kontrol etme kabiliyetine, diğer bir ifade ile iç denetim odağına sahip olması beklenir (Erdem vd., 2002, s. 913).

İçten denetimli bireyler, özellikle karmaşı iş süreçlerinin gerekli olduğu işlerde diştan denetimlilere göre daha başarılıdır (Spektor, 1982). İç denetimli bireyler, karmaşık işler ile karşısaştıklarında, konu ile ilgili daha fazla bilgi toplayıp, daha yüksek başarı gösterme çabasına girerler (Sürgen, 2014, s. 35). Tabak ve arkadaşları (2011, s. 159), iç denetim odağının yenilikçi iş davranı̧̧ı düzeyini, belirsizliğe tolerans ve risk alma aracillğı ile etkilediğini belirtmişlerdir. Çalışkan (2013), ilgi, bağlllık, moral, tartışma, katılım ve açıklık ile şekillenen içe odaklı grup kültürü ile ölçme, belgelendirme, bilgi yönetimi, kontrol ve süreklilik ile şekillenen hiyerarşik kültürün yenilikçi iş davranışını olumlu yönde etkilediğini; personel güçlendirmenin ise bu ilişkide kısmı aracılık rolü üstlendiğini tespit etmiştir. İç denetim odağı yenilikçi iş davranışı düzeyini pozitif ve anlamlı etkiler (Tabak vd., 2011, s. 159). İç denetim odağı iş performansını ve yeniliği pozitif ve anlamlı etkiler (Howell ve Avolio, 1993, s. 891).

Taylor (2010, s. 445) ise, iç denetim odağına sahip bireylerin çözüm odaklı çatışma stratejilerini kullanmaya eğimli olduğunu, dış denetim odaklı bireylerin kaçınma yöntemini izlediklerini; içten denetimli bireylerin bir çatışmanın birçok boyutunu görebildiğini, çatışmalara daha yaratıcı çözümler üretebildiğini, yöneticilerin fikirleri ile kendi fikirlerini kaynaştırabildiğini bulmuştur. Dijkstra ve arkadaşları (2011, s. 167), iç denetim odağına sahip çalışanların, çatışma yönetiminde problem çözme stratejisini daha sıklıkla kullandıklarını bulmuşlardır.

\section{Yöntem}

\section{Araştırmanın Amacı ve Modeli}

$\mathrm{Bu}$ araştırmanın amacı, turizm işletmelerinde öz-yeterlilik ve iç denetim odağının yenilikçi iş davranışı üzerindeki etkisi incelenmektedir. Araştırma nicel araştırma yöntemlerinden ilişkisel tarama modeline dayalı olarak tasarlanmıştır (Şekil 1).



Şekil 1. Araştırma Modeli 
Araştırmanın hipotezleri aşağıda verilmektedir.

H1: Çalışanların öz-yeterlilik algısı, yenilikçi iş davranışını pozitif ve anlamlı etkilemektedir.

H2: Çalışanların iç denetim odağı algısı, yenilikçi iş davranışını pozitif ve anlamlı etkilemektedir.

\section{Çalışma Grubu}

Antalya'da bulunan 5 yıldızlı konaklama işletmelerinde çalışan 82.533 çalışan çalışma evrenini oluşturmaktadır. Yamane’nin (2001, s. 116-117) örneklem formülüne göre çalışmanın örneklem sayısı \% 5 hata payı ile 382 olarak hesaplanmıştır. Örneklemin belirlenmesinde kota örnekleme yöntemi kullanılmıştır. Veriler Alanya, Side, Kemer, Antalya Merkez ve Belek olmak üzere 5 ana bölgede toplanmıştır. Her bölgeden 2 otel olmak üzere, toplam 10 otelden veri toplanmıştır. Gönderilen 600 anketten 512'si geri dönmüş, 439 anket değerlendirmeye alınmıştır. Uygulama sırasında anket formu katılımcılara yüz yüze ulaştırılmıştır. Yanıtlar hazır istatistik paket programı tarafindan analiz edilmiştir.

\section{Veri Toplama Araçları}

Araştırmada veri toplama aracı olarak anket kullanılmıştır. Kullanılan anket 3 ayrı ölçekten ve kişisel bilgi formundan oluşmaktadır.

Kişisel Bilgi Formu: Araştırmacı tarafından hazırlanan kişisel bilgi formu, çalışma grubunda yer alan katılımcıların cinsiyet, medeni durum, yaş, eğitim durumu, pozisyon (çalışan-yönetici olma durumuna), sektördeki toplam çalışma yılı, şu anda çalıştıkları işyerlerindeki toplam çalışma yılı, departmanları, çalışma biçimleri (vardiyalı-vardiyasız çalışma durumuna), mesleki eğitimlere katılma sıklıkları, alanlarındaki fuar ve yayınları takip etme sıklıklarına dair bilgilerini içeren toplam 11 sorudan oluşmaktadır. Bu çalışmada yalnızca analizlerde kullanılan verilerin sunumuna yer verilmiştir. Diğer verilere ilgili tezden ulaşılabilir.

Yenilikeçi İs Davranışı Ölçeği: Janssen (2000, s. 287-302) tarafindan geliştirilmiş, araştırmacı tarafindan Türkçe'ye çevrilmiştir. Orijinal ölçek fikir üretme, fikir destekleme ve fikri uygulama olmak üzere 3 alt boyuttan oluşmaktadır. Her alt boyutta 3 madde yer almaktadır. Ölçeğin güvenilirliği (Cronbach $\alpha)$.95'tir.

Genel Öz-yeterlilik Ölçeği: Schwarzer ve Jarusselam (1995, s. 159) tarafindan geliştirmiştir Türkçe formu, Aypay (2010, s.113) tarafindan çeviri-tekrar çeviri tekniği ile hazırlanmıştır. Ölçek katılımcılara 7 madde olarak uygulanmıştır. Katılımcılardan "tamamen doğru”dan, "tamamen yanlış"a uzanan ölçek üzerinde, kendileri için en uygun olan ifadeyi işaretlemeleri istenmiştir. Dörtlü eşit aralıklı olarak düzenlenmiş olan ölçek, orijinali bozulmayarak katılımcıya dörtlü olarak uygulanmış, ölçek puanları analizler sırasında diğer ölçeklerle uyumlanabilmesi için beşli aralığa çevrilmiştir. Ölçeğin güvenirlik katsayısı .83’tür.

Denetim Odă̆ı Ölçĕgi: Rotter (1966, s. 1) tarafindan geliştirilmiş, Dağ (2002, s. 77) tarafindan Türkçe’ye uyarlanmıştır. Bütünü 47 maddeden oluşan ölçeğin diş denetim odağ1 4, iç denetim odağ1 3 olmak üzere açıklayıcılık değeri en yüksek olan 7 maddesi katılımcılara uygulanmıştır. Katılımcılardan "tamamen uygun"dan, "hiç uygun değil"e uzanan ölçek üzerinde, kendileri için en doğru olan ifadeyi işaretlemeleri istenmiştir. Ölçeğin güvenirlik katsayısı .92’dir (Dă̆, 2002, s. 77).

Araştırmada kullanılan ölçeklerin eşit aralıklı olduğu varsayımından hareket edilerek, aritmetik ortalamalar için puan aralı̆̆1 katsayısı 0.80 olarak bulunmuştur. Puan Aralığ1= (En Yüksek Değer-En Düşük Değer) $/ 5=4 / 5=0.80$. Buna göre aritmetik ortalamaların değerlendirme aralığ1 şöyledir: 1.00-1.80 aras1 "çok düşük”, 1.81-2.60 aras1 “düşük”, 2.61-3.40 aras1 “orta”, 3.41-4.20 aras1 "yüksek”, 4.21-5.00 “çok yüksek”. Araştırmada kullanılan ölçeklerin alan yazında yaygın kullanılan ölçekler arasında bulunmasına, geçerliliği ve güvenirliğinin yüksek olmasina özen gösterilmiştir.

\section{Verilerin Analizi}

Araştırma hipotezini doğrulama için çoklu doğrusal regresyon analizi kullanılmıştır. Araştırma sorularını yanıtlamada, katılımcıların demografik ve işe ilişkin özelliklerine göre ayrı ayrı gruplarda bağlantısız örneklemler için t testi ve ANOVA testi analizi uygulanmıştır.

Analizler öncesinde veriler, temel varsayımlar açısından incelenmiş ve gerekli düzeltmeler yapılmıştır. Öncelikle veri setindeki kayıplar değerlendirilmiştir. Yordanan ve yordayıcı değişkenlerde, her bir madde düzeyinde kayıpların en fazla \% 2 olduğu, cinsiyet ve diğer değişkenlerle manidar bir ilişki göstermediği görülmüştür. Maddelerin sıralama ölçeğinde veri sağladığı dikkate alınarak, kayıp veri atama yöntemlerinden medyan atama kullanilarak eksiksiz veri elde edilmiştir. Yordanan ve yordayıı 
TÖRE

Öz-yeterlilik ve İç Denetim Odağının Yenilikçi İş Davranışına Etkisi: Konaklama İşletmelerine Yönelik Bir Araştırma

değişkenlere yönelik toplam puanlar, standart Z puan dönüşümü kullanılarak uç değerler açısından incelenmiştir. $(-3,+3)$ standart değerleri dişında değer alan iki gözlem birimi belirlenmiş, bunlar uçdeğer olarak tanımlanmış ve veri setinden çıkarılmıştır. Verilerin analizi hazır istatistik paket programları kullanılarak yapılmıştır.

\section{Bulgular}

\section{Demografik Bulgular}

Katılımcıların demografik ve kurumsal özellikleri Tablo 1'de verilmektedir.

Tablo 1. Katılimcilarn Demografik ve İse İlişkin Özellikleri

\begin{tabular}{lll}
\hline Değişken & Değişken Değeri & Yüzde (\%) \\
\hline \multirow{2}{*}{ Cinsiyet } & Kadın & 40.4 \\
& Erkek & 59.6 \\
\hline \multirow{2}{*}{ Medeni Durum } & Evli & 50.4 \\
& Bekar & 49.6 \\
\hline \multirow{2}{*}{ Yaş } & 20 yaş ve altı & 21.2 \\
& $21-30$ yaş arası & 36.4 \\
& $31-40$ yaş arası & 34.8 \\
\multirow{2}{*}{ Pozisyon } & 41-50 yaş arası & 6.9 \\
& 50 yaş ve üzeri & 0.7 \\
\hline
\end{tabular}

Tablo 1 incelendiğinde, katılımcıların çoğunluğunu erkek çalışanların oluşturduğu (\% 59.6), 21-40 yaş arası (\% 71.2) çalışanların çoğunlukta olduğu, \% 12.1 oranında yönetici pozisyonunda çalışan olduğu görülmektedir.

\section{Yenilikçi İş Davranışı Öıçeği'nin Açımlayıcı ve Doğrulayıcı Faktör Analizi Sonuçları}

Yenilikçi İş Davranışı Ölçeği’nin açımlayıcı ve doğrulayıcı faktör analizi sonuçlanı Tablo 2'de verilmektedir.

Tablo 2. Yenilikẹi İs Davranısı Ölçeği Açımlayıı Faktör Analizi Sonuçar

\begin{tabular}{lc}
\hline FAKTÖR 1: Fikir Üretme ve Uygulama (Açıklayıcılık=36.302; Alpha=.84) & Faktör Yükü \\
\hline Madde & .797 \\
1-Zor durumlar için yeni fikirler üretirim. & .717 \\
2- Yeni çalışma metotlarını, tekniklerini ve araçlarını araştırırım. & .793 \\
3- Problemler için orijinal çözümler üretirim. & .672 \\
7-Yenilikçi fikirleri, kullanı̧̧ı uygulamalara dönüştürürüm. & .689 \\
8-Çalışma ortamımda, düzenli olarak yenilikçi fikirler öneririm. & .625 \\
9-Yenilikçi fikirlerin faydasını değerlendiririm. & .822 \\
\hline FAKTÖR 2: Fikri Destekleme (Açıklayıcılık=24,969; Alpha=.70) \\
\hline 4-Yenilikçi fikirleri desteklerim. & .609 \\
5-Yenilikçi fikirlerin edinilmesini takdir ederim. & .789 \\
6-Çlışma arkadaşlarımın yenilikçi fikirler için heyecanlanmasını önemserim. & \\
\hline
\end{tabular}

Yapılan açımlayıcı faktör analizi sonucunda Kaise-Meyer-Olkin Ölçüm Yeterliliği .902, Bartlett Test 1543,124 bulunmuştur (p<0.01). 3 faktörden 2 faktöre inmiş olan Yenilikçi İş Davranışı Ölçeği madde sayısını korumuştur. Birinci faktör 6 maddeden oluşmaktadır "fikir üretme ve uygulama" olarak isimlendirilmiştir. İkinci faktör 3 maddeden oluşmaktadır ve "fikri destekleme" olarak isimlendirilmiştir (Tablo 2). Bulgular alanyazın ile farklılık göstermekte, fikir üretme ve fikir uygulama alt boyutları bu çalışmada tek faktör altında toplanmaktadır. Fikir üretme ve fikir uygulama alt boyutları tek faktör altında toplanan ölçeğin, ikinci faktörü ise fikri desteklemedir. Çalışanlar fikir üretme, araştırma, değerlendirme, uygulama gibi aktif eylem gerektiren tüm maddeleri bir faktör altında yorumlamışlardır. Diğer taraftan mevcut fikir oluşumunu destekleme ve onaylama gibi daha pasif olan eylemleri ise "fikri destekleme" faktöründe değerlendirmişlerdir. Ölçeğin toplam güvenirliği .87, toplam açıklayıcllı̆̆ı ise \% 61.27'dir.

Yenilikçi iş davranışı ölçeği DFA sonucunda ulaşılan uyum indeksleri ve kabul aralıkları Tablo 3.' de verilmektedir. 
Tablo 3. Yenilikeçi Iss Davranışı Ölçeği DFA Sonuclarnda Ulaşılan Uyum İndeksleri ve Kabul Arahklar

\begin{tabular}{cccc}
\hline İndeks & YİD Ölçeği Uyum İndeksleri & Normal Değer & Kabul Edilebilir Değer \\
\hline GFI & 0.95 & $\geq 0.95$ & $\geq 0.90$ \\
AGFI & 0.92 & $\geq 0.95$ & $\geq 0.90$ \\
CFI & 0.98 & $\geq 0.95$ & $\geq 0.90$ \\
RMSEA & 0.08 & $\leq 0.05$ & $\leq 0.10$ \\
RMR & 0.03 & $\leq 0.05$ & $\leq 0.08$ \\
SRMR & 0.04 & $\leq 0.05$ & $\leq 0.08$ \\
\hline
\end{tabular}

Kaynaklar: Bentler ve Bonett, 1980, s.599; Bentler, 1980, s.419; Marsh, Hau, Artelt, Baumert ve Peschar, 2006, s.311; Byrne ve Campbell, 1999, s.555; Brown ve Cudeck, 1993, s.136).

Tablo 3 incelendiğinde yenilikçi iş davranışı ölçeği DFA sonucunda ulaşılan uyum indekslerinin kabul edilebilir uyum derecesinde olduğu görülmektedir. Bu model ile veri uyumunun olduğu anlamına gelmektedir.

\section{Öz-yeterlilik Ölçeği'nin Açımlayıcı ve Doğrulayıcı Faktör Analizi Sonuçları}

Öz-yeterlilik Ölçeği’nin açımlayıcı ve doğrulayıcı faktör analizi sonuçları Tablo 4'de verilmektedir.

Tablo 4. Öz-Yeterlilik Ölçeğg Açımlayıc Faktör Analizi Sonuçlar

\begin{tabular}{lc}
\hline FAKTÖR 1: Çaba (Açıklayıcılık=32.747; Alpha=.76) & Faktör Yükü \\
\hline Madde &, 633 \\
1-Yeterince çaba harcarsam, zor sorunları çözmenin bir yolunu daima bulabilirim. &, 766 \\
3- Amaçlarıma bağlı kalmak ve hedeflerimi gerçekleştirmek, bana zor gelmez. &, 839 \\
5- Yeteneklerim sayesinde beklenmedik durumlarla nasıl baş edebileceğimi biliyorum. &, 678 \\
7-Önüme çıan zorluk ne olursa olsun üstesinden gelebilirim. & .716 \\
\hline FAKTÖR 2: Çözüm Bulma (Açıklayıcıllı=26.131; Alpha=.62) & .753 \\
\hline 2-Bana karşı çıkıldığında, istediğimi elde etmemi sağlayacak bir yol ve yöntem bulabilirim. & .715 \\
4-Yeteneklerim sayesinde, beklenmedik durumlarla nasıl baş edebileceğimi biliyorum. \\
6-Başım dertte olduğunda, genellikle bir çözüm yolu düşünebilirim.
\end{tabular}

Yapılan açımlayıcı faktör analizi sonucunda Kaise-Meyer-Olkin Ölçüm Yeterliliği .825, Bartlett Test 755.0131 bulunmuștur $(\mathrm{p}<0.01)$. İki faktör altında toplanmıș olan Öz-yeterlilik Ölçeği 7 madden oluşmaktadır. Birinci faktör 4 maddeden oluşmaktadır ve "çaba" olarak isimlendirilmiştir. İkinci faktör ise 3 maddeden oluşmaktadır ve "çözüm bulma" olarak isimlendirilmiştir. Alanyazında tek faktör olan özyeterlilik, bu çalış̧ada 2 faktöre ayrılmıştır (Tablo 4). "Çaba" faktörü altında, çalışanların zorluklarla baş edebilme ve hedeflerine ulaşma yolundaki inançları; "çözüm bulma" faktörü altında ise çalışanların amaca ulaştıracak yol ve yöntemi bulma konusundaki inançları yer almaktadır. Başka bir genel öz-yeterlilik ölçeği olan Sherer'n ölçeğini dilimize çeviren Yıldırım ve İlhan (2010) yaptıkları çalısmada, öz-yeterliliği "başlama", "yılmama" ve "sürdürme çabası" olarak 3 faktörde değerlendirmişlerdir. Bu anlamda özyeterliliğin birden fazla faktör altında toplayan başka araştırmaların da olduğunu söylemek mümkündür. Ölçeğin güvenirliği .78 toplam açlklayıc1lı̆ı ise \%58.878'dur.

Öz-yeterlilik Ölçeği DFA sonucunda ulaşılan uyum indeksleri ve kabul aralıkları Tablo 5'de verilmektedir.

Tablo 5. Öz-yeterlilik Ölçeği DFA Sonuclarnda Ulaşılan Uyum İndeksleri ve Kabul Aralıklar

\begin{tabular}{cccc}
\hline İndeks & BPD Ölçeği Uyum İndeksleri & Normal Değer & Kabul Edilebilir Değer \\
\hline GFI & 0.98 & $\geq 0.95$ & $\geq 0.90$ \\
AGFI & 0.96 & $\geq 0.95$ & $\geq 0.90$ \\
CFI & 0.99 & $\geq 0.95$ & $\geq 0.90$ \\
RMSEA & 0.05 & $\leq 0.05$ & $\leq 0.10$ \\
RMR & 0.01 & $\leq 0.05$ & $\leq 0.08$ \\
SRMR & 0.03 & $\leq 0.05$ & $\leq 0.08$ \\
\hline
\end{tabular}

Kaynaklar: Bentler ve Bonett, 1980, s.599; Bentler, 1980, s.419; Marsh, Hau, Artelt, Baumert ve Peschar, 2006, s.311; Byrne ve Campbell, 1999, s.555; Brown ve Cudeck, 1993, s.136).

Tablo 5 incelendiğinde Öz-yeterlilik Ölçeği DFA sonucunda ulaşılan uyum indekslerinin kabul edilebilir uyum derecesinde olduğu görülmektedir. Bu model ile veri uyumunun olduğu anlamına gelmektedir. 


\section{Denetim Odağı Ölçeği’nin Açımlayıcı ve Doğrulayıcı Faktör Analizi Sonuçları}

Denetim Odağı Ölçeği’nin açımlayıcı ve doğrulayıcı faktör analizi sonuçları Tablo 6'da verilmektedir.

Tablo 6. Denetim Odağ Ölçĕgi Açımlayıcı Faketör Analiz̨i Sonucları

\begin{tabular}{lc}
\hline \multicolumn{1}{c}{ FAKTÖR 1: Dış Denetim Odağ1 (Açıklayıcılık=29.754; Alpha=.68) } & Faktör Yükü \\
\hline Madde & .727 \\
1-Bir şeyin olacağı varsa eninde sonunda mutlaka olur. & .692 \\
2-Bazı insanlar, doğuştan şanslıdır. & .738 \\
5-Birçok hastalık, insanı yakalar ve bunu önlemek mümkün değildir. & .670 \\
\hline 7-Kaderin, insan yaşamı üzerinde çok büyük bir rolü vardır. & .542 \\
\hline FAKTÖR 2: İç Denetim Odağ1 (Aç1klayıcılık=22.499; Alpha=.53) & .823 \\
\hline 3- Bir insanın başına gelenler, temelde kendi yaptiklarının sonucudur. & .757 \\
4- İnsanlarla yakın ilişkiler kurmak, tesadüflere değil, çaba göstermeye bağlıdır. \\
6-İnsan, kendi yaşamına temelde kendisi yön verir.
\end{tabular}

Yapılan açımlayıcı faktör analizi sonucunda Kaise-Meyer-Olkin Ölçüm Yeterliliği .704, Bartlett Test 414,162 bulunmuştur $(\mathrm{p}<0.01)$. Alanyazına uygun olarak 2 faktör altında toplanmıs olan Denetim Odağ1 Ölçeği 7 madden oluşmaktadır. Birinci faktör dört maddeden oluşmaktadır ve "dış denetim odağı" olarak isimlendirilmiştir. İkinci faktör ise üç maddeden oluşmaktadır ve "iç denetim odağı" olarak isimlendirilmiştir (Tablo 6). Ölçeğin toplam açıklayıcılığı ise \%52.25’ dür. Faktörlerin alanyazın ile paralellik gösterdiği görülmektedir.

Denetim Odağı Ölçeği DFA sonucunda ulaşılan uyum indeksleri ve kabul aralıkları Tablo 7’ de verilmektedir.

Tablo 7. Denetim Odağı Ölçeği Açımlayıcı Faktör Analizi Sonuçlar

\begin{tabular}{cccc}
\hline İndeks & DO Ölçeği Uyum İndeksleri & Normal Değer & Kabul Edilebilir Değer \\
\hline GFI & 0.98 & $\geq 0.95$ & $\geq 0.90$ \\
AGFI & 0.95 & $\geq 0.95$ & $\geq 0.90$ \\
CFI & 0.99 & $\geq 0.95$ & $\geq 0.90$ \\
RMSEA & 0.06 & $\leq 0.05$ & $\leq 0.10$ \\
RMR & 0.05 & $\leq 0.05$ & $\leq 0.08$ \\
SRMR & 0.05 & $\leq 0.05$ & $\leq 0.08$ \\
\hline
\end{tabular}

Kaynaklar: Bentler ve Bonett, 1980, s.599; Bentler, 1980, s.419; Marsh, Hau, Artelt, Baumert ve Peschar, 2006, s.311; Byrne ve Campbell, 1999, s.555; Brown ve Cudeck, 1993, s.136).

Denetim Odağı Ölçeği DFA sonucunda ulaşılan uyum indeksleri ve kabul aralıkları Tablo 7’ de verilmektedir. Tablo 7 incelendiğinde Denetim Odağı Ölçeği DFA sonucunda ulaşılan uyum indekslerinin kabul edilebilir uyum derecesinde olduğu görülmektedir. Bu model ile veri uyumunun olduğu anlamina gelmektedir.

\section{Boyut ve Alt Boyutlara İlişkin Betimleyici Analiz Sonuçları}

Araştırmada kullanılan tüm ölçeklere uygulanan açımlayıcı faktör analizi (AFA) ve doğrulayıcı faktör analizi (DFA) sonucunda elde edilen boyutlara ve alt boyutlara ilişkin betimsel istatistik verileri Tablo 8'de verilmektedir.

Tablo 8. Boyut ve Alt Boyutlara İlişkin Betimleyici Analiz. Sonuclar

\begin{tabular}{|c|c|c|c|c|c|c|c|}
\hline Boyut ve Alt Boyutlar & $\mathbf{N}$ & Min & Max. & Mean & $\begin{array}{c}\text { Madde } \\
\text { Sayısı }\end{array}$ & Madde Ort. & Std. Sapma \\
\hline $\begin{array}{l}\text { Fikir Üretme } \\
\text { ve Uygulama }\end{array}$ & 439 & 8,00 & 30,00 & 24,95 & 6 & 4,15 & 4,24 \\
\hline Fikir Destekleme & 439 & 3,00 & 15,00 & 13,14 & 3 & 4,38 & 1,87 \\
\hline Yenilikçi Dav. & 439 & 12,00 & 45,00 & 38,10 & 9 & 4,23 & 5,57 \\
\hline Bilgi Paylaşımı & 439 & 4,00 & 20,00 & 17,31 & 4 & 4,27 & 2,84 \\
\hline Öz-yeterlilik & 439 & 14,67 & 35 & 30,97 & 7 & 4.42 & 3,52 \\
\hline Çaba & 439 & 7,00 & 20,00 & 17,88 & 4 & 4.47 & 2,24 \\
\hline Çözüm Bulma & 439 & 6,34 & 15,00 & 13,02 & 3 & 4,34 & 1,81 \\
\hline Diş Denetim Odağ 1 & 439 & 4,00 & 20,00 & 15,91 & 4 & 3,97 & 3,30 \\
\hline İç Denetim Odağ1 & 439 & 3,00 & 15,00 & 12,88 & 3 & 4,29 & 1,81 \\
\hline
\end{tabular}


Tablo 8 göstermektedir ki, araştırmanın örneklemi ölçülen değerleri içerisinde barındırmaktadır. Betimleyici analizdeki bir diğer önemli bulgu ise çalışanların hem iç denetim hem de dış denetim odağı puanlarının yüksek olmasıdır.

\section{Hipotezlerin Testine İlişkin Bulgular}

Araştırma hipotezlerinin testine ilişkin bulgular Tablo 9 ve 10'da verilmektedir.

Tablo 9. Öz-yeterliliğin Yenilikẹi Iș Davramss Üzerindeki Etkisini Inceleyen Regresyon Analizi Sonuclar

\begin{tabular}{lccccc}
\hline \multicolumn{1}{c}{ Partial r } & Part r & F & B & t & p \\
\hline Öz-yeterlilik & & & & & .000 \\
Bağımsız Değişken: Öz-yeterlilik & .324 & 211.386 & .571 & 14.539 & \\
Bağımlı Değişken: Yenilikçi İş Davranışı & & & & & \\
\hline
\end{tabular}

Öz-yeterliliğin yenilikçi iş davranışı üzerindeki etkisini incelemek üzere yapılmış regresyon analizi sonucunda, öz-yeterliliğin yenilikçi iş davranışını anlamlı ve olumlu etkilediği $[(p<0.01)(F=211.386)]$ ve modeli \%32 oranında açıkladığı bulunmuştur (Tablo 9).

Tablo 10. İç Denetim Odağmnn Yenilikeçi Iș Davramışı Üzerindeki Etkisini İnceleyen Regresyon Analizi Sonuçlar

\begin{tabular}{lcccccc}
\hline & Partial r & Part r & F & B & t & p \\
\hline $\begin{array}{l}\text { İç Denetim } \\
\text { Odağı }\end{array}$ & .208 & .206 & 114.70 & .456 & 10.714 & .000 \\
\hline Bağımsız Değișken: İç Denetim Odağının & & & Bağımlı Değiş̧ken: Yenilikçi İş Davranışı
\end{tabular}

İç denetim odağının yenilikçi iş davranışı üzerindeki etkisini incelemek üzere yapılmış regresyon analizi sonucunda, iç denetim odağının yenilikçi iş davranışını anlamlı ve olumlu etkilediği $[(\mathrm{p}<0.01)(\mathrm{F}=$ 114.70) ] ve modeli \% 20 oranında açıkladığ bulunmuştur (Tablo 10).

\section{Tartışma, Sonuç ve Öneriler}

Araştırmanın bulguları araştırmanın her iki hipotezinin de doğrulandığını göstermektedir. Özyeterlilik yenilikçi iş davranışını anlamlı ve pozitif etkilemektedir. Amaçlarına bağlı, hedeflerini gerçekleştirmede çaba sarf eden, beklenmedik durumlarla baş edebileceğine inanan, farklı çözüm yolları arayan çalışanlar daha fazla yenilikçi fikir üretmekte, üretilen fikirleri desteklemekte ve uygulamaktadır. Hasio ve arkadaşları (2011, s.233) öğretmenler üzerinde yaptıkları çalışmalarında, öz-yeterliliği yüksek çalışanların, yenilikçi iş davranışını daha fazla sergilediklerini bulmuşlardır. Basım ve arkadaşları (2008, s.121), kamu çalışanları üzerinde yaptıkları araştırmada, öz-yeterlilik algısı ile yenilikçi davranış arasında olumlu bir ilişki bulmuştur. Bu iki araştırma bulgusu, bu araştırmanın öz-yeterliliğin yenilikçi iş davranışını pozitif etkilediği bulgusunu desteklemektedir. Jong (2014:28) yenilikçi iş davranışı sürecinin son aşaması olan uygulama aşamasını, gereksinimlerin fikirden gerçekliğe transfer edilmesi olarak tanımlar. Uygulama aşamasında, yeni ürünler ve iş süreçlerinin geliştirilir, değiştirilir, test edilir. Bu uygulamalar için inisiyatif kullanan, sabırll, engelleri aşabilen, süreci kendiliğinden başlatan, iş tanımında olmayan işleri de yapan çalışanlara ihtiyaç vardır. Öz-yeterliliği yüksek olan çalışanlar, uygulama aşamasında daha başarılı olacaklardır. Çünkü öz-yeterlilik mevcut durumda yapılan değişimlerin başarıya ulaşacağına dair inancı destekler.

İç denetim odağının yenilik iş davranışını anlamlı ve pozitif etkilemektedir. Kendi yaşamlarına kendilerinin yön verebileceğini düşünen, iyi ilişkilerin çaba ile oluşacağına inanan, başlarına gelen durumların kendi sorumlulukları sonucunda gerçekleştiğini düşünen çalışanlar; daha fazla yenilikçi fikir üretmekte, üretilen fikirleri desteklemekte ve uygulamaktadır. Alanyazında iç denetim odağına sahip bireylerin birçok alanda olumlu performans sergilediğini gösteren pek çok araştırma bulunmaktadır (Sadowski vd, 1983, s. 627; Erbin vd., 1997, s. 183; Hattrup vd, 2005, s. 461; Pannells vd, 2008, s. 67; Dave vd., 2011, s. 28; Tong ve Wang, 2012, s. 202; Anastasiou, 2015, s. 40). Diğer taraftan bu araştırmanın bulguları; Tabak ve arkadaşlarının (20111, s. 59), iç denetim odağının yenilikçi iş davranışı düzeyini, belirsizliğe tolerans ve risk alma aracillğı ile etkilediğini bulgusu ile örtüşmektedir.

Araştırmanın bulguları göstermektedir ki; bireysel faktörler yenilikçi iş davranışını etkilemektedir. Kişiliğin erken yaşlarda şekillendiği göz önüne alındığında, yetişkin dönemdeki eğitimlerin yenilikçi iş davranışını açıklayan iç denetim odağı ve öz-yeterlilik üzerinde çok etkili olmayacağı düşünülmektedir. Müşteri ile yakın ilişki içerisinde olan çalıssanlar başta olmak üzere tüm çalışanların istihdamında konaklama 
işletmeleri, kişilik özelliklerine önem vermeli, iş-kişilik dengesinin kurulması için ilgili meslek gruplarından (psikologlar, psikolojik danışmanlar vb.) destek almalıdır.

Araştırmanın sınırlılıkları çerçevesince bu çalışmada, turizm sektöründeki konaklama işletmelerinde çalışanların yenilikçi iş davranışlarının incelenmesi hedeflenmiştir. Tüm sektör çalışanlarına ulaşmak zor olacağından, Antalya ilindeki beş turizm bölgesinden on konaklama işletmesinin çalışanları araştırmaya dâhil edilmiştir. Çalışmanın farklı turizm bölgelerinde ya da farklı statüdeki konaklama işletmelerinde tekrarlanması çalışmanın genellenmesi açısından faydalı olacaktır. Yenilik yapma kapasitesi yüksek olan diğer sektörlerde de yenilikçi iş davranışının çalışılması önerilmektedir. Yenilikçi iş davranışını etkileyen pek çok değişken olmasına rağmen, bu çalışma iç denetim odağ1 ve öz-yeterlilik değişkenlerinin yenilikçi iş davranışı üzerindeki etkisin incelenmesi ile sınırlandırılmıştır. Özellikle liderlik, çatışma gibi grup değişkenlerinin yenilikçi iş davranışı üzerindeki etkisi bundan sonraki araştırmaların konusu olabilir. Bireysel, örgütsel ve grup değişkenlerinin bir arada ele alındığı araştırma modellerinin alanyazına katkı sağlayacağı düşünülmektedir.

Nicel araştırma tekniklerinden anket kullanılarak yapılmış olan bu çalışmanın bulguları, yeni nitel çalışmalara kapı aralayıcı olacaktır. Yenilikçi iş davranışının kökenleri ve nedenlerine yönelik yapılacak "odak grup görüşmeleri”, "mülakatlar" ve "gözlem" çalışmaları daha derinlemesine bilgi edinilmesini sağlayabilir.

Yenilikçi iş davranışının nedenleri, sonuçları ve etkileri üzerine farklı hedef kitlelere (müşteriler, çalışanlar, tedarikçiler, yöneticiler, STK'ler vb) yönelik yapılacak araştırmalar, konunun her açıdan incelenmesini sağlayacaktır. Bu çalışmada işle ilgili değişkenlerin (işin türü, çeşitliliği vb.) yenilikçi iş davranışı üzerindeki etkisine bakılmamıştır. Bundan sonraki çalışmalarda işle ilgili değişkenlerin yenilikçi iş davranışı üzerindeki etkisi de incelenebilir.

\section{Kaynakça}

Aktaş, H. G. (2008). Öğretmenlerde denetim odă̆ı ve örgütsel vatandaşlı (Yüksek Lisans Tezi). Afyon Kocatepe Üniversitesi Sosyal Bilimler Enstitüsü, Afyon.

Aypay, A. (2010). Genel Öz Yeterlik Ölçeği'nin GÖYÖ Türkçe’ye Uyarlama Çalışması. İnönü Üniversitesi Eŭitim Fakültesi Dergisi, 11(2), 113-132.

Anastasiou, C. A., Fappa, E., Karfopoulou, E., Gkza, A. ve Yannakoulia, M. (2015). Weight loss maintenance in relation to locus of control: The MedWeight study. Behaviour research and therapy, 71, 40-44.

Bandura, A. (1994). Self-efficacy. In V. S. Ramachaudran (Ed). Encyclopedia of Human Behavior (pp. 71-81). New York. Academic Press.

Bandura, A. (1997). Self-efficacy: the exercise of control. New York: Freeman.

Basım, H. N., Korkmazyürek, H. ve Tokat, A. O. (2008). Çalışanların öz-yeterlilik algılamasının yenilikçilik ve risk alma üzerine etkisi: kamu sektöründe bir araştırma. Selçuk Üniversitesi Sosyal Bilimler Enstitüsü Dergisi, 19, 121130.

Bentler, P. M. ve Bonett, D. G. (1980). Significance tests and goodness of fit in the analysis of covariance structures. Psychological Bulletin, 88(3), 588.

Bentler, P. M. (1980). Multivariate analysis with latent variables: Causal modeling. Annual Review of Psychology, 31(1), 419-456.

Bozkurt, T. (2013). Beden eğitimi ögretmeni adaylarmm ögretmenlik öz-yeterliliklerinin incelenmesi (Yüksek Lisans Tezi). Gazi Üniversitesi Eğitim Bilimleri Enstitüsü. Ankara.

Browne, M. W. ve Cudeck, R. (1993). Alternative ways of assessing model fit. USA: Sage.

Byrne, B. M. ve Campbell, T. L. (1999). Cross-cultural comparisons and the presumption of equivalent measurement and theoretical structure a look beneath the surface. Journal Of Cross-Cultural Psychology, 30(5), 555-574.

Canbay, S. (2007). İlköğretim okullarnda çalısan öğretmenlerin iş doyumu ve denetim odağı ilişkisi (Yüksek Lisans Tezi). Dokuz Eylül Üniversitesi Eğitim Bilimleri Enstitüsü, İzmir.

Çakır, G. (2009). İşgörenlerin demografik özelliklerine göre motivasyon araçları ve denetim odağ1 değişkeninin incelenmesi. Celal Bayar Üniversitesi Sosyal Bilimler Enstitüsü, Yayınlanmamış Yükesek Lisans Tež.

Çalışkan A. (2013). İç odaklı örgüt kültürünün yenilikçi davranışa etkisinde personel güçlendirmenin aracilık rolü. $\dot{I}_{s}$, Güc İnsan Kaynaklar ve Endüstri İliskileri Dergisi, 15(1), 88-112.

Çapraz, B., Ünnü, N. A., İlic, D., Kocamaz, M., Çiçekli, U., Aracıoğlu, B., Koçak, A., Kesken, J. ve Soyuer, H. (2014). Çalışanlar perspektifinden inovatif iş davranışının belirleyicileri: izmir ilinde öncelikli sektörlere ilişkin bir araştırma. Girişimcilik ve Inovasyon Yönetimi Dergisi, 3(1), 49-72.

Dağ, İ. (2002). Kontrol odağı ölçeği (koö): ölçek geliştirme, güvenirlik ve geçerlik çalışması. Türk Psikoloji Dergisi, 17(49), 77-90.

Dave, R., Tripathi, K. N., Singh, P. ve Udainiya, R. (2011). Subjective well-being, locus of control and general selfefficacy among university students. Amity Journal of Applied Psychology, 2(1), 28-32. 
De Jong, J. P. J. (2014). Individual innovation: the connection between leadership and employees' innovative work behavior. University of Amsterdam, Erişim Tarihi: 27.09.2014, http://dare.uva.nl/document/2/52860.

Dijkstra, M. T., Beersma, B. ve Evers, A. (2011). Reducing conflict-related employee strain: the benefits of an internal locus of control and a problem-solving conflict management strategy. Work \& Stress, 25(2), 167-184.

Dönmez, A. (1986). Denetim odağ1: temel araştırma alanları. Ankara Üniversitesi Eğitim Bilimleri Dergisi, 19(1), $259-283$.

Duran, C. ve Saraçoğlu, M. (2009). Yeniliğin yaratıcılıkla olan ilişkisi ve yeniliği geliştirme süresi. Yönetim ve Ekonomi Dergisi, 16(1), 57-71.

Drucker, P. F. (1998). The discipline of innovation. Harvard Business Review, 76(6), 149-157.

Erbin-Roesemann, M. A. ve Simms, L. M. (1996).Work locus of control: the intrinsic factor behind empowerment and work excitement. Nursing Economics, 15(4), 183-190.

Ertürk, Z. (2012). Ankara ili genel lise ögretmenlerinin örgütsel güven aldılar ve denetim odă̆ ile ilişkisi (Yüksek Lisans Tezi). Ankara Üniversitesi Eğitim Bilimleri Enstitüsü, Ankara.

Erdem, F., Atsan, N., Çizel, B. ve Karakaş, K. (2002). Girişimcilik eğilimine sahip üniversite öğrencilerinin başarma ihtiyacı ve kontrol odağı özelliklerine yönelik bir araştırma. 10. Yönetim ve Organizasyon Kongresi Bildiri Kitabı, Akdeniz Üniversitesi İ.İ.B.F., Antalya, ss. 913-920.

Eveleens, C. (2010). Innovation management; literature review of innovation process models and their implications. Sciences, 800, 2010, 900.

Hasiao, H. C., Chang, J. C. , Tu, Y. L. ve Chen, S.C. (2011). The influence of teacher self efficacy on innovative work behavior. International Conference on Social Science and Humanity, 5, 233-237.

Hattrup, K., O’Connell, M. S. ve Labrador, J. R. (2005). Incremental validity of locus of control after controlling for cognitive ability and conscientiousness. Journal of Business and Psychology, 19(4), 461-481.

Howell, J. M. ve Avolio, B. J. (1993). Transformational leadership, transactional leadership, locus of control, and support for innovation: key predictors of consolidated-business-unit performance. Journal of Applied Psychology, $78(6), 891$.

Hsu, I. C. ve Sabherwal, R. (2011). From intellectual capital to firm performance: the mediating role of knowledge management capabilities". Engineering Management, IEEE Transactions on, 58(4), 626-642.

Janssen, O. (2000). Job demands, perceptions of effort-reward fairness and innovative work behaviour. Journal of Occupational and Organizational Psychology, 73(3), 287-302.

Jong J. P. J. (2007). Individual innovation: the connection between leadership and employees' innovative work behavior, Amsterdam Business School Research Institute, PhD Thesis

Kheng, Y. K., Mahmood, R. ve Beris, S. J. H. (2013). A conceptual review of innovative work behavior in knowledge intensive business services among knowledge workers in Malaysia. International Journal of Business, Humanities and Technology, 3(2).

Li, C. H. ve Wu, J. J. (2011). The structural relationships between optimism and innovative behavior: understanding potential antecedents and mediating effects. Creativity Reseach Journal, 23(2), 119-128.

Luthans, F. (1998). Organizational Behavior, Eight Edition, Mc Grow-Hill Inc.

Marsh, H. W., Hau, K. T., Artelt, C., Baumert, J. ve Peschar, J. L. (2006). OECD's brief self-report measure of educational psychology's most useful affective constructs: Cross-cultural, psychometric comparisons across 25 countries. International Journal of Testing, 6(4), 311-360.

Momeni, M., Ebrahimpour, H., ve Ajirloo, M. B. (2014). The effect of employees'self-efficacy on innovative work behavior at social security organization employees in Ardabil province. Kuwait Chapter of The Arabian Journal of Business And Management Review, 3(8), 29.

Oliver, J. E., Jose, P. E. ve Brough, P. (2006). Confirmatory factor analysis of the work locus of control scale. Educational and Psychological Measurement, 66(5), 835-851.

Onan, A. (2011). Probleme dayal ăgsal ögrenmenin tıp fakültesi ögrencilerinin transfer becerileri ve öz-yeterlilik algzlarnna etkisi (Yüksek Lisans Tezi). Ankara Üniversitesi Eğitim Bilimleri Enstitüsü, Ankara.

Pannells, T. C. ve Claxton, A. F. (2008). Happiness, creative ideation, and locus of control, Creativity Research Journal, 20(1), 67-71.

Parlar, H. (2009). Ticaret meslek lisesi yöneticilerinin öz-yeterlilik ve çatışma yönetimi anlayıslar arasındaki ilişki (Yüksek Lisans Tezi). Maltepe Üniversitesi Sosyal Bilimler Enstitüsü, İstanbul.

Pekmezci, G. (2010). Hemşirelerin örgütsel bağlllıkları ile öz-yeterlilikleri arasındaki ilişkiler (Yüksek Lisans Tezi). İstanbul Üniversitesi Sosyal Bilimler Enstitüsü, İstanbul.

Potosky, D. ve Ramakrishna, H. V. (2002). The moderating role of updating climate perceptions in the relationship between goal orientation, self-efficacy and job performance. Human Performance, 15(3), 2.

Rotter, J. B. (1966). Generalized expectancies for internal versus external control of reinforcement". Psychological Monographs: General and Applied, 80(1), 1.

Sadowski, C. J., Woodward, H. R., Davis, S. F. ve Elsbury, D. L. (1983). Sex differences in adjustment correlates of locus of control dimensions, Journal of Personality Assessment, 47(6), 627-631.

Schimansky, S. (2014). The effect of a high-commitment work system on innovative behavior of employees. Third IBA Bachelor Thesis Conference, 3 July 2014, Enschede, The Netherlands.

Schumpeter, J. A. (1934). The theory of economic development: an inquiry into profits, capital, credit, interest, and the business cycle. Transaction Publishers. Vol. 55. 
West, M. A., ve Farr, J. L. (1989). Innovation at work: psychological perspectives. Social Behaviour, 4(1), 15-30.

Schwarzer, R. ve Jerusalem, M. (1995).Optimistic self-beliefs as a resource factor in coping with stress. In Extreme Stress and Communities: Impact and Intervention, Springer Netherlands, pp. 159-177.

Scott, S. G. ve Bruce, R. A. (1994). Determinants of innovative behavior: a path model of individual innovation in the workplace. Academy of Management Journal, 37(3), 580-607.

Sönmez, B. (2011). Hemşirelerin yenilikçi davranışları ve etkileyen faktörler: niteliksel bir çalışma. İstanbul Üniversitesi Sağlık Bilimleri Enstitüsü, Yaymlanmamıs Doktora Tęi.

Tabak, A. Erkuş, A. ve Meydan, C. H. (2011). Denetim odağı ve yenilikçi birey davranışları arasındaki ilişkiler: belirsizliğe karşı tolerans ve risk almanın aracıllk etkisi. Anadolu Üniversitesi Sosyal Bilimler Dergisi, 10(1), 159176.

Taylor, M. (2010). Does locus of control predict young adult conflict strategies with superiors? an examination of control orientation and the organizational communication conflict instrument. North American Journal of Psychology, 12(3), 445.

Tong, J. ve Wang, L. (2012). Work locus of control and 1ts relationship to stress perception, related affections, attitudes and behaviours from a domain-specific perspective. Stress and Health, 28(3), 202.

Yamane, T., (2001). Temel Örnekleme Yöntemleri, (1. Baskı). (Çev. A. Esin, M. A.Bakır, C. Aydın ve E. Gürbüzsel), Literatur Yayınc1lik, İstanbul.

Yıldırım, F. ve İlhan, İ. Ö. (2010). Genel öz-yeterlilik ölçeği türkçe formunun geçerlilik ve güvenilirlik çalışması. Türk Psikiyatri Dergisi, 21(4), 301-308.

\section{EXTENDED ABSTRACT}

The need for employees who exhibit innovation and innovative business behavior is increasing day by day. Innovative work behavior involves any individual activity at the level of any organization, including the development, promotion and implementation of a useful innovation. Innovative work behavior is any individual activity at any organizational level that promotes and applies a useful innovation (West, \& Farr, 1989, p. 17). Observing new technologies, trying to reach targets using new strategies, applying new business methods, creating resources for the implementation of new ideas and supporting these ideas are examples of innovative work behavior (Kheng et al., 2013, p. 93). The fact that innovation is not only an idea but also an application (Eveleens, 2010, p. 2) that highlights the importance of the employees who will realize this application.

Bandura's (1997, p. 158) self-efficacy, which comes to the fore in Social Learning Theory, is the judgments of the individual about his / her ability to organize and succeed. Individuals' judgments about how well they can perform the actions necessary to deal with possible situations define their perception of self-sufficiency (Parlar, 2009, p. 12; Pekmezci, 2010, p. 23). If the individual believes that he can reach a result, he is more active and can take control of his life. Jong (2014, p. 28) defines the application, the last stage of the innovative business behavior process, as the transfer of requirements from idea to reality. Innovative business behavior includes the development, modification, testing of new products and business processes. For these applications, there is a need for employees who take initiative, are patient, can overcome obstacles, start the process automatically, and do jobs that are not in the job description. Self-sufficient employees will be more successful in the implementation phase. Because self-efficacy supports the belief that changes in the current situation will be successful. Hasio et al. (2011, p. 235) found that self-efficacious employees produce more ideas, support and implement innovative ideas in their studies on teachers. Printing et al. (2008, p. 121) found a positive relationship between self-efficacy perception and innovative work behavior in their research on public employees. Employee self-efficacy positively and significantly affects innovative work behavior; high level of self-efficacy reveals high level of innovative work behavior (Momeni et al., 2014, p. 29; Hsu et al., 2011, p. 627).

The concept of locus of control forms the cornerstone of Rotter's social learning theory. Rotter (1966) defines locus of control as the belief that one's vital actions are controlled by himself or by others / other environmental elements. Observing that people are different from each other in terms of their ability to control their own lives, Rotter called the dimensions as "internal locus of control" and "external locus of control" (Çakır, 2009, p. 95, Erbin-Roesemann, \& Simms, 1997, p. 185). Individuals with internal locus of control are aware of their responsibilities and undertake the positive or negative consequences of their actions. The external locus of control is that the individual believes that the results of the events he / she encounters are not caused by his / her behavior but by the influence of external forces such as fate, chance, authority, etc. (Çakır, 2009, p. 96-97, Oliver et al., 2006, p. 835-836). Individuals with internal locus of control believe that they can control the work environment and feel empowered about the work done. Individuals with external locus of control think that the work environment is controlled by external forces and that they have no influence (Wnag et al., 2013, p. 1429). 
This study was conducted to investigate the effect of self-efficacy and internal locus of control on innovative work behavior. The study was designed based on the relational screening model of quantitative research methods. 82.533 people working in 5 star accommodation establishments in Antalya constitute the target population of the study. Quota sampling method was used to determine the sample. 439 questionnaires were taken into consideration and the questionnaire was delivered face to face during the application. Personal Information Form, Innovative Work Behavior Scale, General Self-Efficacy Scale and Locus of Control Scale were used for data collection. Innovative Wok Behavior Scale was developed by Janssen (2000, p.287-302) and translated into Turkish by the researcher. The scale consists of nine items in 3 sub-dimensions as idea generation, idea support and idea implementation. General Self-Efficacy Scale was developed by Schwarzer and Jarusselam (1995, p. 159) and adapted to Turkish by Aypay (2010, p. 113). The scale consists of seven items. Locus of Control Scale was developed by Rotter (1966, p. 1) and adapted to Turkish by Dağ (2002, p. 77). The 47 items, seven of which had the highest explanatory value, 4 of which were external control focus and 3 of which were internal control focus, were applied to the participants.

Responses were analyzed by a ready-to-use statistical package program. Multiple linear regression analysis was performed to confirm the research hypothesis. As a result of the research, it was found that self-efficacy significantly and positively influenced innovative work behavior $[(\mathrm{p}<0.01)(\mathrm{F}=211.386)]$ and explained the model by $32 \%$. Internal locus of control significantly and positively influenced innovative work behavior $[(\mathrm{p}<0.01)(\mathrm{F}=114.70)]$ and explains the model by $20 \%$. Hasio et al. (2011, p. 233) found that teachers with higher self-efficacy showed more innovative work behavior in their studies on teachers. Printing et al. (2008, p. 121) found a positive relationship between self-efficacy perception and innovative behavior in their research on public employees. These two research findings support the finding that selfefficacy positively affects innovative work behavior. On the other hand, Tabak et al. (20111, p. 59) coincide with the finding internal locus of control affects the level of innovative work behavior through tolerance and risk-taking uncertainty.

It is recommended to study innovative work behavior in other sectors with high capacity to innovate. Although there are many variables that affect innovative work behavior, this study is limited to examining the effect of internal locus of control and self-efficacy variables on innovative business behavior. In particular, the effect of group variables such as leadership and conflict on innovative business behavior may be the subject of further research. Individual, organizational and group variables are considered together and it is thought that research models will contribute to the literature. 